\title{
Retinoid signalling is required for information transfer from mesoderm to neuroectoderm during gastrulation
}

\author{
FERRAN LLORET-VILASPASA ${ }^{1,4}$, HANS J. JANSEN ${ }^{1}$, KOEN DE ROOS ${ }^{1}$, ROSH A.S. CHANDRARATNA ${ }^{2}$, \\ MAIJA H. ZILE ${ }^{3}$, CLAUDIO D. STERN ${ }^{4}$ and ANTONY J. DURSTON ${ }^{1}$ \\ 'Instituut Biologie Leiden (IBL), Faculty of Mathematics and Natural Sciences, University of Leiden, Clusius laboratorium, \\ Leiden, The Netherlands, ${ }^{2}$ Allergan Pharmaceuticals, California, USA, ${ }^{3}$ Dept. Food Science and Human Nutrition, State \\ University, East Lansing, MI, USA and ${ }^{4}$ Department of Cell and Developmental Biology, University College London, UK
}

\begin{abstract}
The hindbrain region of the vertebrate central nervous system (CNS) presents a complex regionalisation. It consists of 7-8 distinct morphological segments called rhombomeres, each with a unique identity provided by combinations of transcription factors. One class of signalling molecules, retinoids, have been shown to be crucial for hindbrain patterning through direct trans-activation of Hox genes in the neuroectoderm. However, how this morphogen acts is not yet fully understood. Here, we show that the retinoid receptor antagonist AGN193109 causes a posterior hindbrain defect in Xenopus, comparable to that seen in other vertebrates. We show that this defect arises during gastrulation. Blocking endogenous retinoid activity during gastrulation causes downregulation of the most 3' Hox genes (paralogues 1-5) in gastrula neuroectoderm, but their initial activation in gastrula non-organiser mesoderm is unaffected. Similar results were obtained in avian embryos: Vitamin Adeficient quail embryos have defective expression of $3^{\prime}$ Hox genes (i.e. Hoxb1, Hoxb4) in the neural tube, but their early expression in the primitive streak and emerging paraxial and lateral mesoderm is not affected. In Xenopus, depletion of retinoids from mesoderm by targeted injection of mRNAs for the retinoic acid catabolising enzyme XCYP26 and the cellular retinoic acid binding protein XCRABP blocks 3' Hox gene expression in the overlying neuroectoderm. We propose that the gastrula nonorganiser mesoderm and its later derivative, the paraxial mesoderm, is the source of a retinoid, which acts as a "transforming" (caudalising) signal for the future posterior hindbrain.
\end{abstract}

KEY WORDS: retinoid, neuroectoderm, mesoderm, gastrulation, hindbrain

\section{Introduction}

There is much evidence that signalling via active retinoids (vitamin A metabolites) is important for early patterning events during development of the vertebrate central nervous system (CNS) (reviewed in (Durston etal., 1998)). Vertebrate embryos go through a sensitive period, starting during gastrulation, when the developing CNS is drastically posteriorised by exposure to the active retinoid all-trans-retinoic acid (RA) (Durston et al., 1989; Sive etal., 1990; Avantaggiato etal., 1996). This agent mimics the action of an endogenous intercellular signal which patterns the developing CNS at this stage (Doniach, 1995; Lumsden and Krumlauf, 1996; Durston et al., 1998). Key regulatory genes involved in CNS patterning are transactivated directly in neuroectoderm by specific binding of retinoic acid receptor (RAR) and retinoid receptor $(R X R)$ heterodimers to retinoic acid responsive elements (RAREs) (Marshall et al., 1996). Among the retinoid targets are the Hox genes, which are crucial for patterning the posterior CNS (hindbrain and spinal cord). Retinoid-regulated Hoxgenes are situated 3' in Hoxclusters (Lumsden and Krumlauf, 1996; Durston et al., 1998; Gavalas and Krumlauf, 2000). Members of Hox paralogue groups (pg) 1-5 are activated by ectopic RA, while members of pg 6-9 are not (Godsave et al., 1998; BelVialar et al., 2002).

To identify developmental functions of retinoids, one approach

\footnotetext{
Abbreviations used in this paper: AGN, synthetic retinoid AGN193109; CNS, central nervous system; CRABP, cellular retinoic acid binding protein; RA, retinoic acid; RAR, retinoic acid receptor.
}

\footnotetext{
*Address correspondence to: Antony J. Durston. Sylvius laboratory (Universiteit Leiden), Sylviusweg 72, 2333 BE Leiden. Tel. +31-71-527-4871. Fax: +31-71-527-4900. e-mail: a.j.durston@biology.leidenuniv.nl - Web: http://www.biology.leidenuniv.nl/ibl/index.shtml
} 
is to examine the consequences of blocking retinoid signalling. This has been possible by a variety of approaches in different vertebrates, for example: vitamin A starvation in quails (Maden et al., 1996), blocking RAR/RXR transactivation by ectopic expression of dominant negative RAR receptors in Xenopus (Kolm et al., 1997; Blumberg et al., 1997; van der Wees et al., 1998), blocking synthesis of active retinoids by mutation of the mouse gene for the enzyme retinal dehydrogenase 2 (Raldh2) (Niederreither et al., 1999; Niederreither et al., 2000) or mutation of the zebrafish Raldh2 gene (Begemann at al., 2001; Grandel et al., 2002), overexpression of the RA catabolising enzyme CYP26 in Xenopusand zebrafish (Hollemann etal., 1998; Kudoh etal., 2002) and applying RAR/RXR synthetic inactive ligands that competitively prevent normal RA binding in chick and zebrafish (Dupé and Lumsden, 2001; Hernandez et al., 2007). All of these studies uncovered a common phenotype caused by loss of retinoid signalling in early vertebrate embryos: lack of segmentation of the posterior hindbrain (rhombomeres (r) 5-8) and transformation of this tissue into more anterior hindbrain. Therefore retinoid signalling is essential for patterning the posterior hindbrain.

A conserved set of retinoid-related genes have been implicated directly in laying down the basic organisation of the vertebrate hindbrain. Among these are genes for vitamin A metabolic enzymes (Hernandez et al., 2007), as well as a network of transcription factors that appear to set up the boundaries between, and the identities of, different rhombomeres (Vesque et al., 1996; Helmbacher et al., 1998, Theil et al., 1998). Hoxgenes and their collinear expression appear to have a prominent role in hindbrain regionalisation. They (at least the most 3' genes of each cluster) are expressed very early in development, in the dorsal neuroectoderm of the gastrula (Wacker et al., 2004). During this early activation, Hox transcripts are detectable not only in the neuroectoderm but also and even earlier, in the mesoderm. Surprisingly, little attention has been given to this initial phase of Hox expression and much less to Hox gene expression in the early gastrula non-organiser (presomitic) mesoderm. Most work to date has concentrated on the later role of Hox genes in patterning the hindbrain, while the mesoderm itself has only been studied later, as a source of signals that pattern the overlying hindbrain: heterotopic grafts in avian embryos demonstrated that morphogens emanating from the somites (including $R A$ ) are needed to set up the right pattern in the adjacent rhombomeres (Itasaki et al., 1996; Gould et al., 1998). Nevertheless, these experiments were performed long after gastrulation, during somite stages and it has not been investigated whether the early activation of Hoxgenes or retinoid signalling from the early gastrula nonorganiser mesoderm play a role in hindbrain patterning.

On the other hand, it is also important to reveal the inductive events that lead to appropriate Hox expression in the early mesoderm. Indeed, misexpression of some Hox genes brings about homeotic transformations in mesodermal derivatives, such as changes in vertebral identity (Ramirez-Solis et al., 1993; Rijli et al., 1995; Subramanian et al., 1995). Interestingly, it was recently shown by means of mutations in regulatory regions of both Hoxa-10 and Hoxa-11 that these genes specify the identity of the corresponding vertebrae by their expression in the presomitic mesoderm, rather than in the somites that derive from it (Carapuço et al., 2005), emphasising the importance of the earliest phase of Hox expression in the mesoderm.
Here we blocked retinoid function during early development of Xenopus laevis. The synthetic retinoid AGN193109 (AGN) has been characterised as being a high affinity antagonist for all three RAR receptor subtypes (Agarwal et al., 1996). We find that when added to Xenopus embryos during gastrulation, AGN causes a mid-axial/hindbrain phenotype: from neurula stages, this resembles the posterior hindbrain phenotypes previously obtained by other approaches (see above), confirming the effectiveness of this reagent for abrogating retinoid signalling. We then investigate the origin of this mid-axial defect in the CNS during Xenopus development and find that AGN does not affect the very earliest Hox gene expression in (non-organiser) mesoderm. Vitamin Adeficient (VAD) quail embryos (deprived of maternal supply of vitamin $\mathrm{A}$ and therefore unable to synthesise retinoids) display a similar phenotype. Towards the end of gastrulation, AGN treatment causes loss of expression of mid-axial genes in neuroectoderm. At this stage and in the early neurula, the defect is more extensive than that seen later, at the late neurula stage; by then, the early phenotype is partly repaired, resulting in a more localised defect.

These results suggest that retinoids are involved in mediating information transfer from mesoderm to neuroectoderm during gastrulation, perhaps corresponding to the transformation signal in Nieuwkoop's activation-transformation model of CNS patterning (Nieuwkoop, 1952). To test this we blocked retinoid function in gastrula mesoderm by ectopic expression in mesodermal cells (but not neuroectodermal cells) of the RA catabolic enzyme xCYP26 and the RA binding protein XCRABP. This blocks neuro-
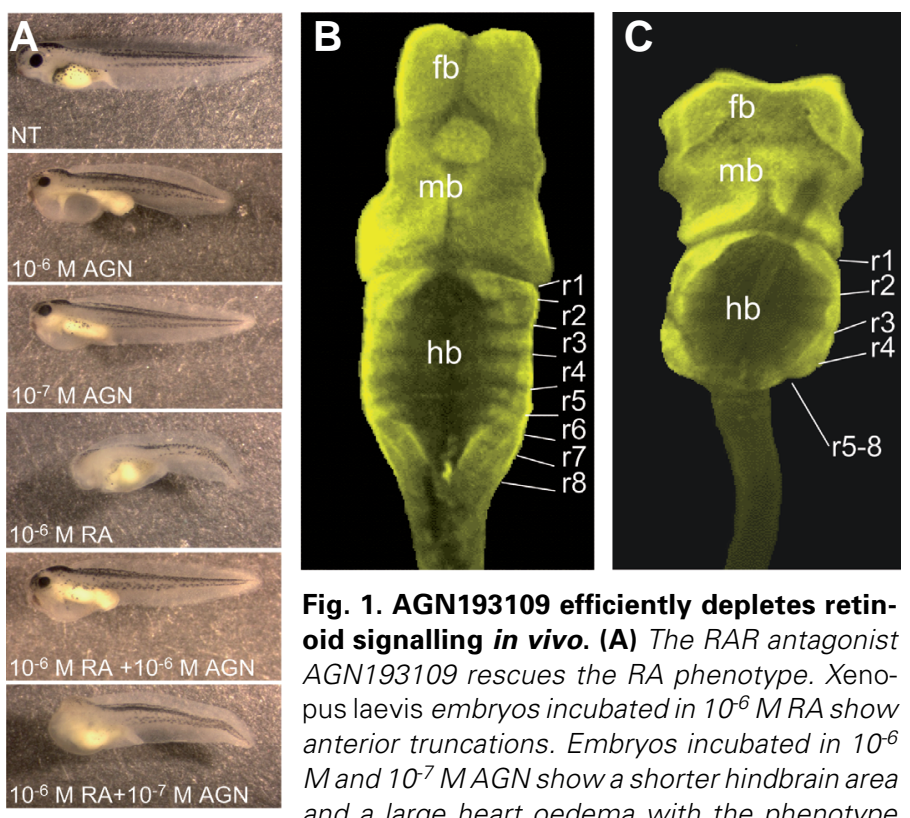

Fig. 1. AGN193109 efficiently depletes retinoid signalling in vivo. (A) The RAR antagonist AGN193109 rescues the RA phenotype. Xenopus laevis embryos incubated in $10^{-6} \mathrm{M} R A$ show anterior truncations. Embryos incubated in $10^{-6}$ $M$ and $10^{-7} \mathrm{MAGN}$ show a shorter hindbrain area and a large heart oedema with the phenotype being more severe at $10^{-6} \mathrm{M}$. When embryos are incubated in equal concentrations $\left(10^{-6} \mathrm{M}\right)$ of $R A$ and $A G N$ the resulting phenotype is more like the AGN phenotype. When $10^{-6} \mathrm{M} R A$ is combined with $10^{-7} \mathrm{M} A G N$ the phenotype is more like an RA phenotype. NT (control). (B) AGN treatment caused severe brain malformations. CLSM images of stage 45 tadpole brains labelled with Xen 1 and 2 G9 antibodies. (B) Control embryo, treated with $0.1 \%$ DMSO. (C) $10^{-6}$ M AGN treated embryos (fb: forebrain; mb: midbrain; hb: hindbrain, rn refer to rhombomere numbers). In AGN treated embryos, the number of rhombomeres was reduced to 4 or 5 . 
ectodermal expression of hindbrain (3') Hox genes, supporting the idea that retinoid function in mesoderm is required for patterning of the adjacent neuroectoderm.

We propose that in Xenopus the identity of the posterior hindbrain (r4-8) is acquired during gastrulation, that retinoids are necessary for the correct patterning of this region of the CNS by regulating the expression of Hoxgenes in specific rhombomeres (pg 1-5) and that earlier expression of the same genes in the underlying non-organiser mesoderm is not affected by retinoid loss of function. Thus, initiation of Hox expression, which takes place in the non-organiser mesoderm during early gastrulation, is RA-independent. We therefore suggest that RA acts as a vertical signal from this mesoderm to instruct the overlying prospective hindbrain region.

\section{Results}

\section{The general retinoid antagonist AGN193109 impairs retinoid signalling}

To assess the effect of the RAR antagonist $A G N$ on retinoid signalling in early Xenopus, embryos were injected with a DR-5TATA-luciferase reporter and the embryos then treated with $10^{-6}$ M AGN or $10^{-6} \mathrm{M}$ RA during gastrulation. Luciferase activity after antagonist treatment decreased to $30 \%$ of that measured in untreated or carrier $(0.1 \%$ DMSO) treated embryos, whereas it increased nearly 4-fold after treatment with $10^{-6} \mathrm{M}$ RA (see Fig. S1 in Supplementary data). These results show that AGN impairs retinoid signalling in vivo.

We investigated if $A G N$ can inhibit teratogenicity of exogenously applied RA (Fig. 1A). As previously described, treatment of gastrula stage embryos with $10^{-6} \mathrm{M}$ RA causes severe anterior truncations, lost or reduced eyes and a reduced cement gland (Durston et al., 1989; Sive et al., 1990). However, co-application of $10^{-6} \mathrm{M}$ RA with $10^{-6} \mathrm{M}$ AGN rescues the development of eye pigment and cement gland, similar to embryos treated with AGN only; whereas co-application of $10^{-7} \mathrm{M}$ AGN with $10^{-6} \mathrm{M}$ RA yielded an intermediate rescue. These results show that $A G N$ can antagonise RA teratogenicity. Furthermore, treatments with 10 ${ }^{7} \mathrm{M}$ AGN or $10^{-6} \mathrm{M}$ alone caused increasing shortening of the A-P axis.

\section{Retinoid loss of function by the general retinoid antagonist AGN generates mid-axial defects}

The luciferase assay above showed that treatment with $10^{-6} \mathrm{M}$ AGN not only interferes with the effects of exogenously applied $R A$, but also causes a decrease in endogenous retinoid signalling. This predicts that AGN treatment should also cause an axial patterning phenotype similar to those previously observed using diverse RA loss of function approaches. We used immunohistochemistry with the antineural antibodies 2G9 (Jones and Woodland, 1989) and Xen-1 (Ruiz i Altaba, 1992) and confocal microscopy to analyse changes in the morphology of the tadpole (st. 45)
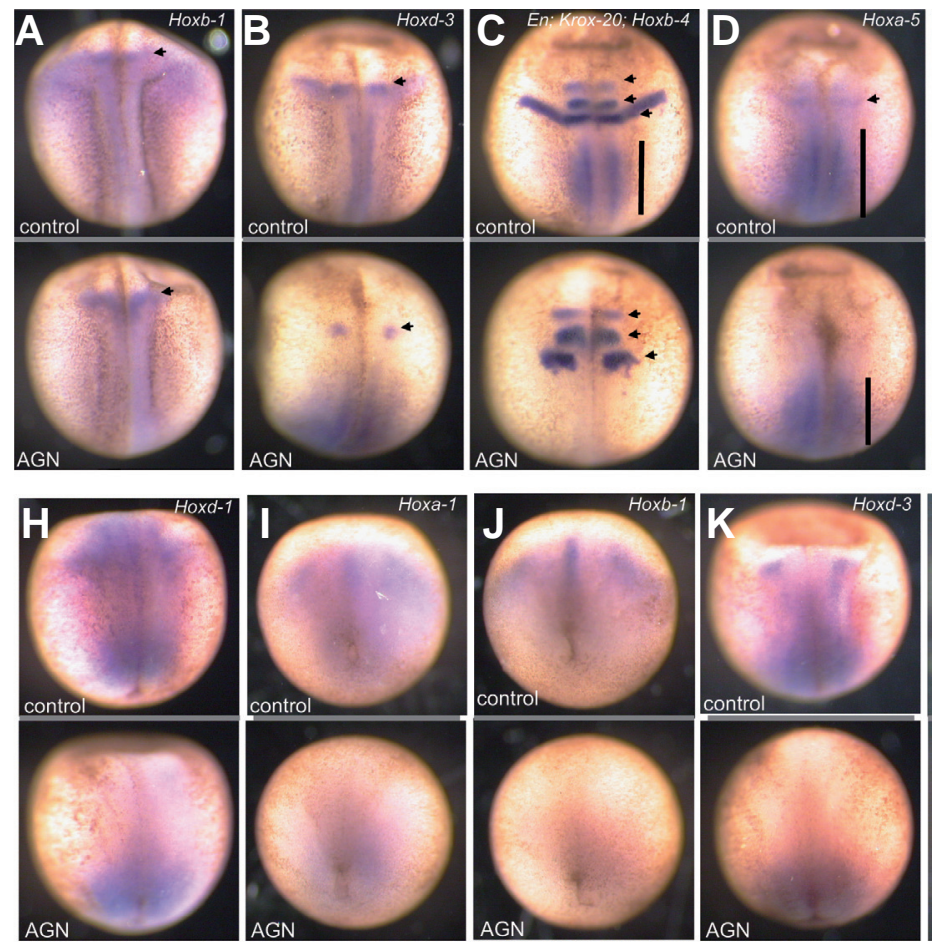
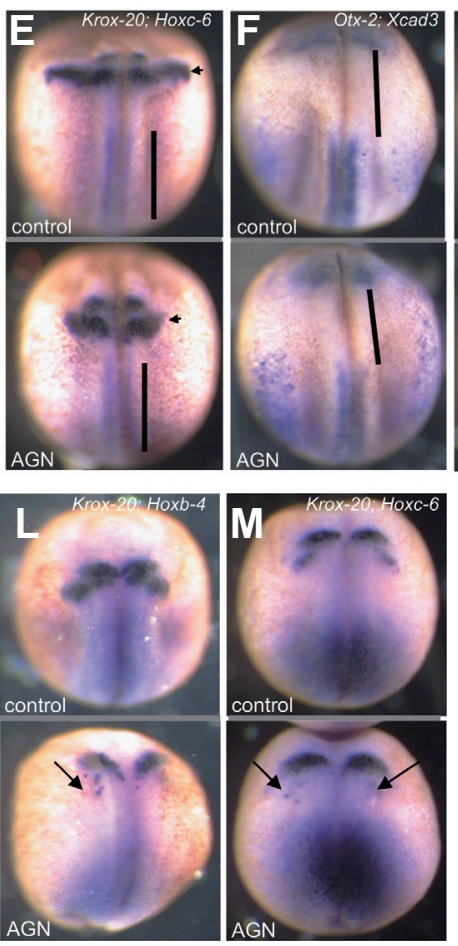

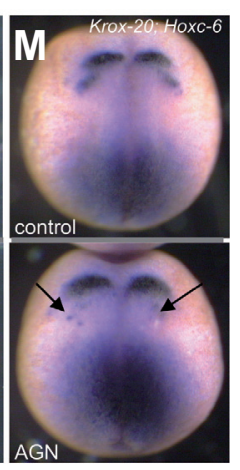

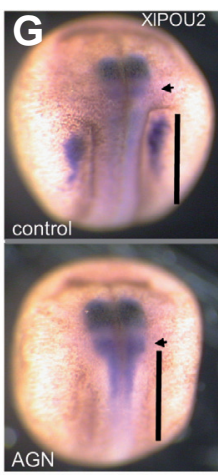

Fig. 2. Retinoid depletion causes radical molecular truncation of the posterior hindbrain by the end of gastrulation. (Top panel) Wholemount in situ hybridizations (WISH) on st. 20Xenopus laevis embryos (AF). The upper row shows non-treated embryos (indicated by control) and the bottom embryo is treated with $10^{-6} \mathrm{M}$ AGN (indicated by AGN). All views are dorsal and anterior at the top. (A) Hoxb-1, arrowhead indicates hindbrain expression; (B) Hoxd-3, ar-

rowhead indicates hindbrain expression; (C) En2, Krox-20 and Hoxb-4, top arrowhead indicates En stripe, bottom arrowheads indicate Krox-20 stripes and bar indicates Hoxb-4 stripe; (D) Hoxa-5, arrowhead indicates hindbrain expression and bar indicates spinal cord expression; (E) Krox-20 and Hoxc6, arrowhead indicates posterior Krox-20 stripe, bar indicates Hoxc-6 expression; (F) Otx-2 andXcad3, bar indicates gap between Otx-2 (anterior) and Xcad3 (posterior) expression patterns; (G) XIPOU2, arrowhead indicates hindbrain expression and bar indicates spinal cord expression. (Bottom panel) Whole-mount in situ hybridizations on st. 13Xenopus laevis embryos (H-M). The upper row shows non-treated embryos (indicated by control) and the right embryo is treated with 10-6 M AGN (indicated by AGN). All views are dorsal and anterior at the top. (H) Hoxd-1; (I) Hoxa-1; (J) Hoxb-1; (K) Hoxd-3; (L) Krox-20 (anterior stripes) and Hoxb-4; (M) Krox-20 (anterior stripes) and Hoxc-6. Arrows in pictures (L,M) localise sparse cells representing the posterior stripe of Krox-20. 
CNS caused by AGN treatment. Examination of the brain revealed a compressed prosencephalon and mesencephalon. The anterior hindbrain is slightly enlarged and properly segmented, rhombomeres 4 and 5 are quite normal in size but less distinctly segmented, whereas rhombomeres 6, 7 and 8 are truncated or absent (Fig. 1B,C). These findings confirm that AGN causes posterior hindbrain defects similar to those seen using other methods to deplete retinoid signalling.

\section{The definitive hindbrain defect caused by AGN treatment is established by the late neurula}

We examined the developmental changes in the patterning of the CNS caused by blocking retinoid signalling. By the end of neurulation (st. 20), we observed the following effects of AGN (Fig. 2A-G): the Hoxb-1anterior domain, normally restricted to the prospective 4 , expands towards the future spinal cord (Fig. 2A). In contrast, the Hoxd-3 expression domain ( $r 5-6)$ is reduced as compared to control embryos (Fig. 2B). Hoxb-4 expression becomes undetectable in the presumptive hindbrain and the distance between the En-2stripe at the mid-/hindbrain boundary and the anterior Krox-20 stripe ( $\mathrm{r} 3$ ) increases, indicating an enlargement of r1-2 (Fig. 2C). In control embryos, Hoxa-5is expressed in two stripes in the future anterior spinal cord and posterior hindbrain; both stripes disappear after AGN treatment (Fig. 2D). On the other hand, retinoid depletion expands the normal Hoxc6 expression domain anteriorly (prospective spinal cord), but its intensity appears unaffected (Fig. 2E). Expression of Otx-2 and $X$ cad3 (markers of fore- midbrain and posterior spinal cord domains, respectively) shows no obvious increase in the overall length of the hindbrain (Fig. 2F). Expression of XIPOU2(r2; Fig.
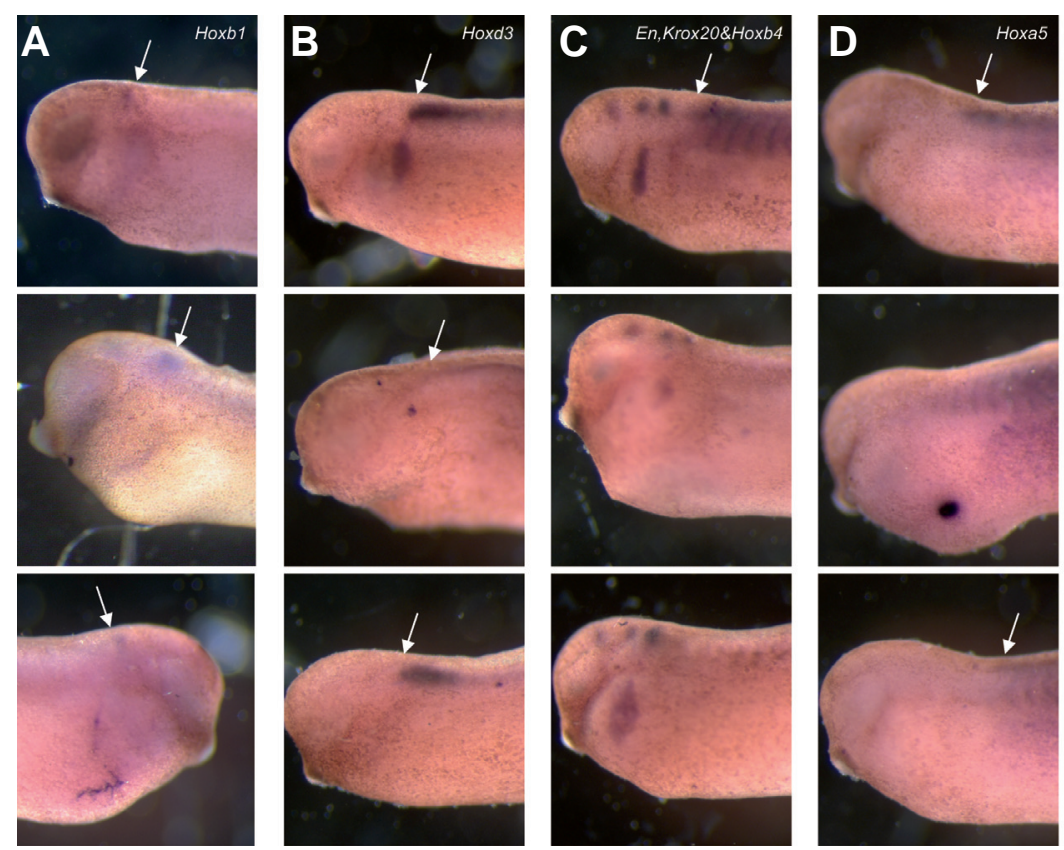

Fig. 3. The molecular identity of the hindbrain is determined by retinoid signalling mostly during gastrulation. Whole-mount in situ hybridizations on tadpole (st. 32) Xenopus laevis embryos. The upper row shows non-treated embryos; the middle row embryos treated with $10^{-6} \mathrm{M}$ AGN from the blastula until the point of fixation; the lowest row embryos treated with $10^{-6} \mathrm{MAGN}$ from st. 13 until the point of fixation. All views are lateral. (A) Hoxb-1, (B) Hoxd-3, (C) En2, Krox-20 and Hoxb-4, (D) Hoxa-5, (E) Krox-20 and Hoxc6. Arrows point to the anterior expression border of each Hox gene.
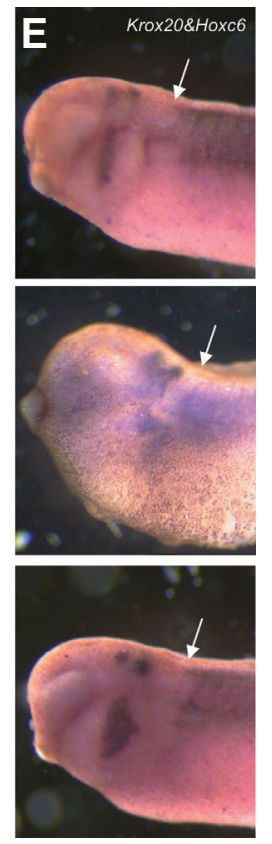

2G) and Krox-20 (r3/r5; Fig. 2 C,E) in their respective $r 2$ and $r 3$ domains show an enlarged anterior hindbrain; the gap of XIPOU2 (x) more, the 5 stripe of Krox-20 becomes thicker in AGN treated embryos. The XIPOU2 stripe associated with $\mathrm{r} 4$ is no longer distinguishable, as it fuses with the spinal cord domain, from and the malformations observed in the future hindbrain of $A G$ treated embryos suggests that the action of retinoid signalling on

\section{The hindbrain defect caused by AGN is more extensive in the early neurula}

Because considerable evidence indicates that retinoids affect axial patterning during gastrulation and the coincidental expresdoman, we looked for the possible effects of abrogation of RA (Figs. 2H-L). However, Hoxc-6 is unaffected (Fig. 2M). Dissection of embryos confirmed that expression of the most 3' Hoxgenes is severely downregulated in the neuroectoderm upon AGN treatment (data not shown).

To compare the length of the presumptive posterior hindbrain with and without AGN treatment, a combination of probes was used for in situ hybridisation. After AGN treatment, the gap between the Krox-20 stripes and Hoxc-6is much smaller (Fig. 2M) and, surprisingly, the Krox20 stripe at $r 5$ is also greatly reduced (compare with Fig. 2 C,E). This shows that truncation of the posterior hindbrain domain by retinoid depletion is effective already at the end of gastrulation.

To correlate the late hindbrain phenotype in the tadpole with the molecular truncation observed in the young neurula, we treated embryos beginning either before or after gastrulation and incubated them until the point of fixation (st. 45). AGN treatment before gastrulation causes the phenotype shown in Fig. 1B. Treatment after the end of gastrulation (st. 13 onwards) however, does not cause gross morphological malformations (results not shown). Surprisingly, when we compared the 

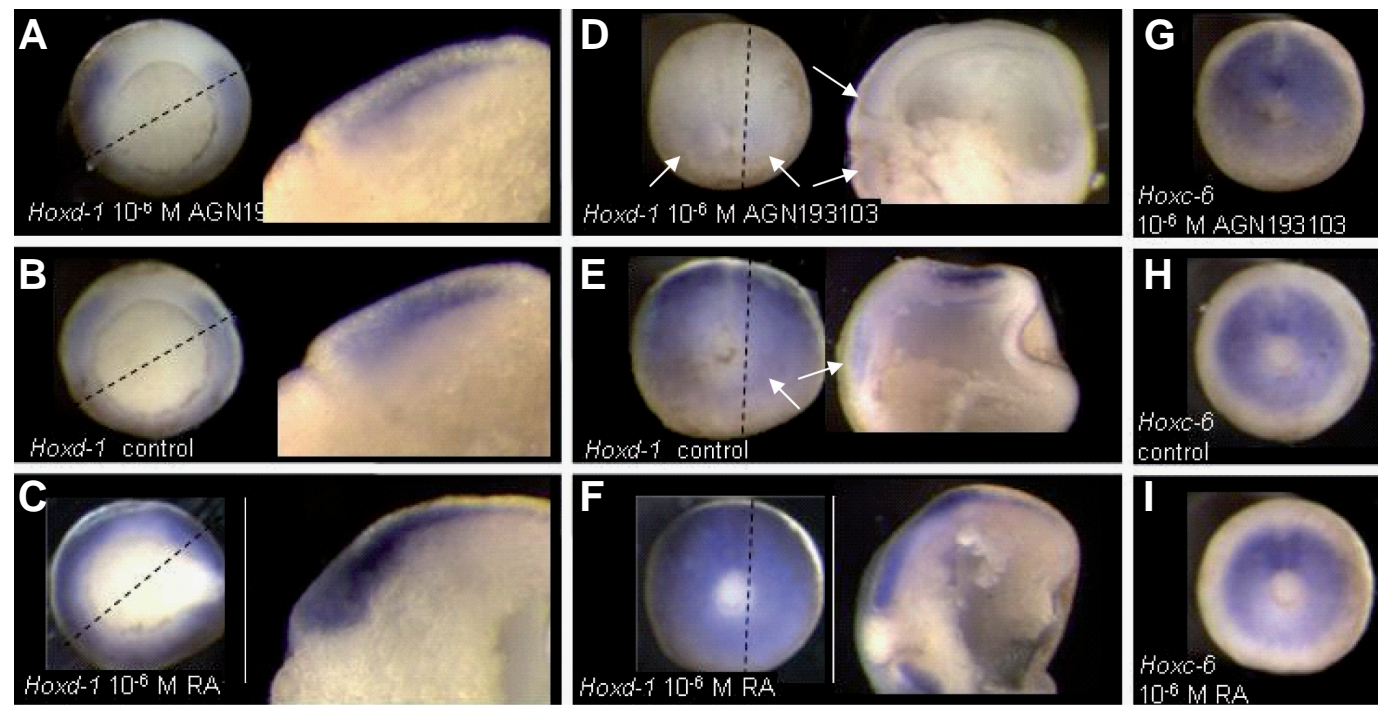

Fig. 4. AGN incubation affects early expression of Hoxd-1 in the neuroectoderm but not in the underlying mesoderm. Whole-mount in situ hybridizations on Xenopus laevis embryos. Hoxd-1 expression at st. 11 (A-C) or st. 12.5 (D-F). Embryos were incubated with $10^{-6} \mathrm{MAGN}(\mathbf{A}, \mathbf{D}), 10^{-6} \mathrm{M}$ $R A(\mathbf{C}, \mathbf{F})$ or not treated $(0.1 \%$ DMSO) (B,E). After photographing the embryos were cut along the indicated dashed line and a lateral view of the cut surface is shown next to the right of each embryo. Arrows in $(D, E)$ point to the faint mesodermal expression remaining at that stage (mostly noninvoluted mesoderm). Hoxc-6 expression on stage 12 embryos (G-I). Treatment with $10^{-6} \mathrm{MAGN}(\mathbf{G}), 10^{-6} \mathrm{MRA}$ (I) or not treated (H).

molecular profiles yielded by the different approaches, we observed that postgastrulation treatment with AGN still causes an alteration, albeit minor, in the molecular pattern of the posterior hindbrain of tadpole embryos. Namely, expression in the posterior hindbrain of the most anterior Hox genes analysed (Hoxb1 and Hoxd3) is not affected by retinoid depletion after the end of gastrulation, but expression of the most posterior ones (Hoxb4and to a lesser extent Hoxb5) is still sensitive to AGN treatment after this period (Fig. 3). The extension of the posterior hindbrain indicated by the distance between the posterior expression stripe of Krox-20 in r5 and the anterior expression boundary of Hoxc-6in the spinal cord (Fig. 3E)- is not changed by AGN treatment after gastrulation, as compared to non-treated embryos; on the con-
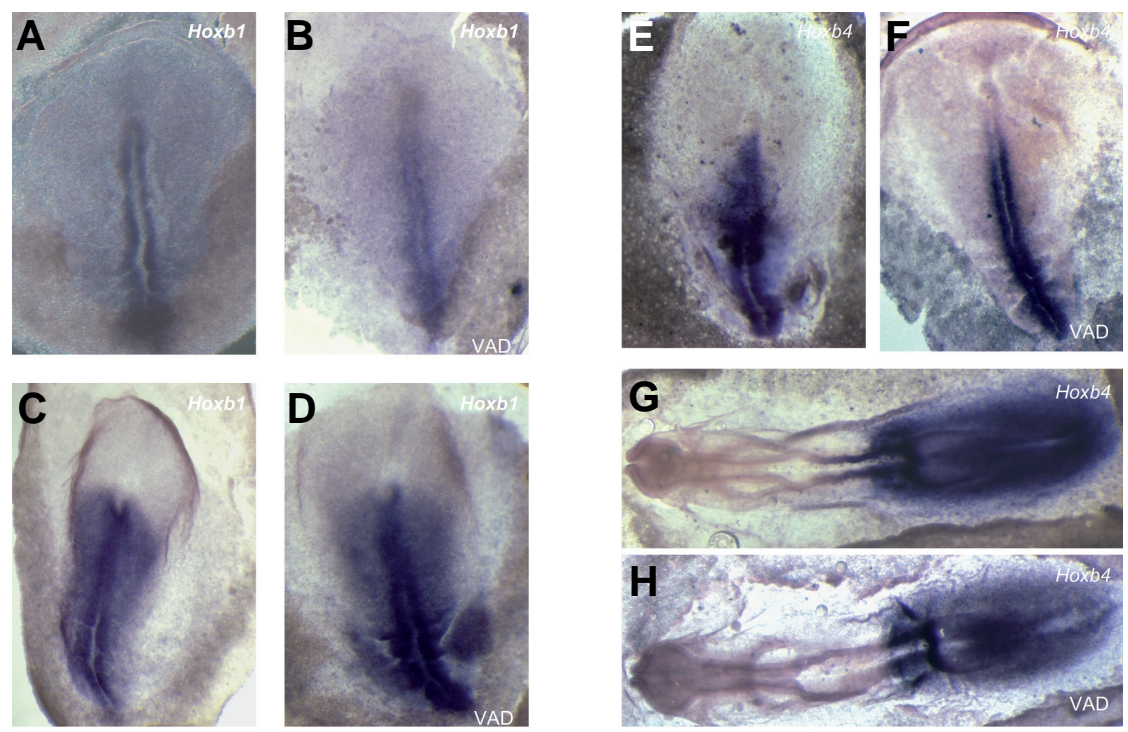

Fig. 5. Initial mesodermal versus later neural plate expression of Hoxb-1 and Hoxb4 expression patterns. Wild-type early (A) and late (C) HH st. 4 embryos are compared to equivalent VAD embryos (B,D); both show expression of Hoxb-1 in the primive streak and later in migrating ingressed cells. Hoxb-4 expression patterns are also shown for HH st. 4 wild-type (E) and VAD (F) embryos, along the primitive streak. At HH st. 8 Hoxb-4 expression pattern includes the neural tube in wild-type $(\mathbf{G})$ but not in VAD (H) embryos. All views are dorsal. trary, AGN treatment beginning before gastrulation causes a remarkable shrinkage of the region, as was already seen at earlier stages. These results indicate that retinoid signalling is required mainly before the end of gastrulation for the hindbrain to acquire a proper morphology; however, part of its pattern remains flexible Mesodermal Hox gene expression during gastrulation is not
retinoid dependent but expression of 3'Hox genes in gastrula neurectoderm is

The above experiments suggest that the phenotype observed after AGN treatment in the hindbrain arises during gastrulation, and that retinoid mediated patterning of the presumptive hindbrain begins at this time. We therefore undertook a more detailed study of the phenotype generated by AGN during gastrulation by analysing both the initiation and the maintenance of Hoxgene expression during this developmental period.

Hoxd-1 appears as a "pioneer" gene, its expression first becoming detectable at stage $10^{+}$(Wacker et al., 2004). AGN treatment does not affect the initial expression in non-organiser mesoderm (Fig. $4 \mathrm{~A}, \mathrm{~B}$ ). However, as gastrulation proceeds in normal embryos, Hoxd-1expression becomes localised more dorsally and is then transferred onto the neuroectoderm; this pattern is absent in AGN treated embryos. By the end of gastrulation, the expression pattern of Hoxd-1 is very strongly reduced and remains exclusively in its mesodermal domain upon retinoid inhibition (Fig. 4 D,E). In contrast, when RA instead of AGN is added to the medium, Hoxd-1 expression is induced in a much larger domain and earlier than in control embryos; expression is particularly strong in the ectoderm and is maintained throughout gastrulation (Fig. 4 C,F).

We then extended the study to Hoxa-1 and Hoxb-4. Both are first expressed weakly at about stage 11 and are upregulated as gastrulation advances (Wacker et al., 2004). We analysed the timing of the consequences of AGN treatment on 


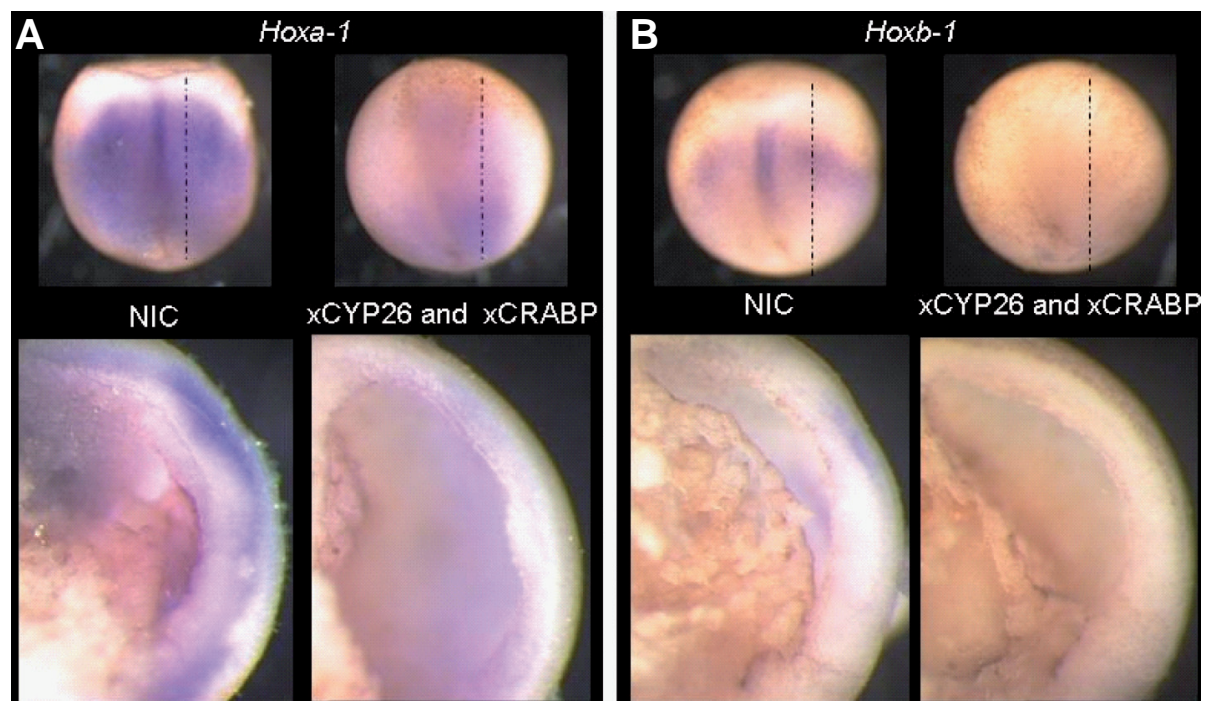

Fig. 6. Effects of targeted retinoid signalling removal in the mesoderm. Whole-mount in situ hybridizations on Xenopus laevis embryos. Hoxa-1 (A) and Hoxb-1 (B) expression at st. 13. NIC: non-injected controls. $x$ CYP26 and xCRABP: Injection of $100 \mathrm{pg} \times$ CYP26: $100 \mathrm{pg} \times \mathrm{CRABP}$ mRNA four times, one time into each macromere at 8-cells stage. Whole embryos (top picture) are shown in a dorsal view with anterior being up. Cut embryos (bottom picture) are shown in a lateral view. involved in the transfer of positional information from mesoderm to neuroectoderm in the hindbrain region at early stages of development. To test this more directly we first injected mRNA encoding xCYP26, which is involved in the degradation of RA (Hollemann et al., 1998), into Xenopus early embryos. $x$ CYP26 mRNA alone or, more effectively, co-injection of $x C Y P 26$ and $x C R A B P$ (cellular retinoic acid binding protein) mRNAs into Xenopus restored the axial defects caused by RA incubation. We conclude that combined ectopic expression of $x C Y P 26$ and $x C R A B P$ causes retinoid loss of function. To test the idea that retinoid signalling from the mesoderm is involved in hindbrain patterning, we loaded gastrula mesoderm cells but not neuroectoderm cells by injection of $x C Y P 26$ and $x C R A B P$ into all four vegetal blastomeres (fated to become mesoderm and endoderm, but not neuroectoderm; see Fig. S2 in Supplementary data) in 8-cellstage embryos. This causes dramatic loss of Hoxa-1 and Hoxb-1 expression in the neurotheir expression: whereas their initiation in the mesoderm is not affected, embryos fail to develop normal neuroectodermal expression when incubated in AGN throughout gastrulation (data not shown). Unlike the three genes mentioned above, neither Hoxc-6 (Fig. $4 \mathrm{G}, \mathrm{H}, \mathrm{I}$ ) nor Hoxb-9 (not shown) expression is affected by either gain- or loss of retinoid function at this stage of development.

\section{Avian embryos also employ a mechanism other than retinoid signalling to regulate early mesodermal Hox expression}

The above experiments show that abrogation of the retinoid pathway with a synthetic inhibitor in Xenopusembryos impairs the normal neuroectodermal expression of 3' Hox genes in the midaxial region early during development. However, the earliest appearance of the same 3' Hox transcripts in mesodermal tissue is not affected by this treatment. To investigate whether such a difference in regulation between the two germ layers is due to limitations of our experimental approach, we turned to the VAD quail model. We performed in situ hybridisation with two 3' Hox genes on both VAD and normal quail gastrula and neurula embryos to see the effects of an absolute depletion of retinoid signal (Fig. 5). Our results show that expression of Hoxb-1 and Hoxb-4 is initiated during gastrulation first in the primitive streak and later in mesodermal cells and that this activation is seen in both control and VAD embryos. In the CNS, expression of these genes normally begins only after the start of neurulation (Fig. 5G); in VAD quail embryos however, this expression is downregulated in the anterior neural tube (Fig. $5 \mathrm{H}$ ). Thus, the avian embryo provides further evidence that 3' Hoxgenes are regulated differently in the mesoderm and in neural tissue. Furthermore, there is an asynchrony of Hoxexpression between the two tissues, which is much more pronounced in avian than in Xenopus embryos.

\section{Retinoid dependent transfer of information from mesoderm to neuroectoderm in the gastrula}

The above experiments suggest that retinoid signalling may be ectoderm (Fig. 6). Together, these results strongly suggest that a retinoid-dependent signal from mesoderm is required for neuroectodermal Hox expression.

\section{Discussion}

The retinoid antagonist AGN193109 gives a strong phenotype in the Xenopus CNS, resembling those previously reported using other highly effective approaches to inhibit retinoid signalling (Maden et al., 1996, Kolm et al., 1997; Blumberg et al., 1997; van der Wees etal., 1998, Hollemann et al., 1998; Niederreither et al., 1999; Niederreither etal., 2000; Begemann atal., 2001; Dupé and Lumsden, 2001; Grandel et al., 2002; Kudoh et al., 2002; Hernandez et al., 2007). This phenotype features disturbances of the posterior hindbrain and anterior spinal cord, and is detectable in its definitive form in late neurula stage embryos. This "mid-axial" phenotype arises during gastrulation. AGN treatment during the gastrula stage already causes disturbances of the gastrula stage neural expression of all 3' anterior Hoxgenes examined (Hoxd-1, Hoxa-1, Hoxb-1, Hoxd-3 and Hoxb-4), whereas expression of more 5' posteriorn Hoxgenes (Hoxc-6and Hoxb-9) is not affected. Severe changes in gene expression are seen later in the future posterior hindbrain region at the early neurula stage. This early defect is the converse of that caused by early retinoid application (Conlon and Rossant, 1992; Godsave et al., 1998). The defect is more extensive than that observed at later stages, both in this investigation and in previous retinoid loss of function studies. If this difference is due to a recovery occurring at later stages, this must be independent of retinoid signalling, as retinoid inhibitor treatments from the end of gastrulation to larval stages could not prevent it. Auto- and cross-regulation among Hoxgenes is likely to be involved, reflecting a second Hoxphase of axial patterning in the CNS. It has been demonstrated in both chicken and mouse that there is indeed a second phase of regulation for Hoxgenes, which starts soon after initiation of somitogenesis and is not 
dependent on retinoic acid but rather on auto-regulation of and interactions between Hox genes (Gould et al., 1998).

In our experiments, virtually no trace of 3' HoxmRNA expression (paralogues 1-5) was detectable in the prospective hindbrain region of retinoid antagonist-treated early neurulae (the region that is to recover part of its pattern in the following stages). One possible explanation is that HOX proteins remain in an area and time where the corresponding mRNAs have disappeared; these HOX proteins would be insufficient to activate early neural Hox gene expression by means of the known cis-acting HOX responsive elements, since early expression requires retinoid activation via RAREs (see above). However, once retinoid sensitivity ends and RA-independent auto-regulatory and cross-regulatory elements take over neural regulation of 3' Hoxgenes, HOX proteins remaining in the region could still be available in sufficient amounts to trigger the new phase of Hox induction. Another possible explanation is that factors other than HOX proteins themselves are needed to start the second phase of Hox activation in the hindbrain region, for instance FGF (Godsave and Durston, 1997) or WNT (McGrew etal., 1997). If a second activation phase devoid of HOX protein remnants in the region occurs, the ordered array of Hox expression observed after partial restoration of the initial mid-axial defects would be consistent with Hoxcollinearity. Whatever the explanation, it appears that during early development the embryo retains a safety mechanism, employing a second round of ordered Hoxactivation to allow possible environmental deficits of vitamin A to be circumvented.

We followed the dynamics of the consequences of retinoid antagonist treatment on Hoxexpression during gastrulation. This is precisely the period in which the first transcripts are detected in all vertebrates studied (Deschamps and Wijgerde, 1993; Gaunt and Strachan, 1996; Wacker et al., 2004). Moreover, in Xenopus, expression is initiated in non-organiser mesoderm, before appearing in the overlying neuroectoderm. We found that the antagonist compromises neuroectodermal Hoxexpression, but has no effect on non-organiser mesodermal expression. To confirm our observations and at the same time test the universality of this phenomenon in vertebrates, we took advantage of the VAD quail model. These embryos lack endogenous retinoid signalling and therefore offer an alternative approach to antagonist-treatment in Xenopus. Analysis by whole-mount in situhybridisation indicated that early mesodermal expression of two 3' Hox genes (Hoxb-1 and Hoxb-4) is not affected in VAD embryos, whereas later neural plate expression is impaired; this phenotype is comparable to that observed in Xenopus neurulae. Therefore, our evidence from both Xenopus and avian embryos indicates that Hox regulation in the early paraxial mesoderm is distinct from that in the prospective hindbrain and independent of retinoid signalling. The nature of this regulation is yet to be elucidated.

We hypothesised that a possible early function for retinoid signalling would be to mediate transfer of A-P information (and thus of Hox expression) from mesoderm to neuroectoderm. This idea is supported by many other data, including mesodermal location of the RA generating enzyme RALDH2 in different vertebrates (Swindell etal., 1999; Berggren etal., 1999; Haselbeck et al., 1999; Chen et al., 2001; Begemann et al., 2001) together with neural action of retinoid dependent enhancers (Gould et al., 1998). We tested this idea by knocking-out mesodermal retinoid signalling but not neural retinoid signalling by targeting mesoderm precursor blastomeres with mixed mRNAs for xCYP26 and $x C R A B P$, two proteins which mediate retinoid degradation. This treatment effectively eliminates the early neural expression of two 3' Hox genes examined (Hoxa-1 and Hoxb-1), indicating that retinoid signalling is required for a "vertical" signal (corresponding to part of Nieuwkoop's "transformation" signal) generated by mesoderm and which induces 3' Hox genes in neuroectoderm.

The present experiments in Xenopusindicate that the retinoidmediated component of the "transformation" signal acts before the end of gastrulation and arises from non-organiser mesoderm (which includes the prospective non-segmented paraxial mesoderm). However, experiments in avian embryos have suggested that the later somitic mesoderm can also signal to impart pattern onto the hindbrain in a retinoid-dependent way (Itasaki et al., 1997; Gould et al., 1998). Moreover, regionalisation of the avian posterior hindbrain seems to coincide with the beginning of somitogenesis (Nordström et al., 2006). This timing difference could be due to distinctive characteristics of each species: in Xenopus the mesoderm migrates as a sheet (involution) which may allow for an early and robust source of signal to pattern the overlying neuroectoderm during gastrulation, whereas the cellby-cell mode of mesoderm migration in the avian embryo is less favourable for local delivery of the morphogen (RA). We suggest that in Xenopus retinoids emanate from the non-segmented nonorganiser mesoderm to pattern the overlying neuroectoderm along with gastrulation movements, whereas avian embryos undergo this process later, after re-epithelialisation of the mesoderm into somites can provide a robust retinoid signal to the adjacent neural tissue. This signal might directly mediate a positionally specific vertical instruction or it might have an auxiliary function (Gould et al., 1998). Whatever the mechanism, the mode of action (mesoderm to neuroectoderm) and nature (RA) of the signal appears to be common to both species and it correlates well with the predicted properties of part of the "transformation" signal that Nieuwkoop proposed long time ago for amphibians (Nieuwkoop, 1952).

\section{Materials and Methods}

\section{Embryo preparation, culture and treatment}

Xenopusembryos were obtained by in vitrofertilisation using standard procedures, cultured in $1 \%$ MMR containing gentamycin $(0.5 \mathrm{~g} / \mathrm{l})$ or $0.1 \%$ MBS (Sive et al., 1998) and staged according to Nieuwkoop and Faber (Nieuwkoop and Faber, 1956).

RA and AGN193109 treatment was from stage 8 to stage 13 by culturing embryos in $1 \%$ MMR or $0.1 \%$ MBS containing RA or AGN193109. Stock solutions were prepared by dissolving RA (Sigma) and AGN193109 (Allergan) in DMSO to concentrations of respectively $10^{-2} \mathrm{M}$ and $10^{-3} \mathrm{M}$ and were stored at $-80^{\circ} \mathrm{C}$. Final dilutions for embryo incubations were made in $1 \%$ MMR or $0.1 \%$ MBS.

Xenopus embryos used in whole mount in situ hybridisation analysis were fixed in MEMPFA (Harland, 1991) for $4 \mathrm{~h}$ at room temperature or overnight at $4^{\circ} \mathrm{C}$, washed once in methanol and stored at $-20^{\circ} \mathrm{C}$ in fresh methanol. Fertilized vitamin A-deficient (VAD) and normal quail embryos were obtained and staged as previously described (Dersch and Zile, 1993; Zile et al., 2000).

\section{Microinjection}

For microinjection, one-cell-stage embryos were transferred to $4 \%$ ficoll in $1 \%$ MMR or $2 \%$ ficoll in $0.1 \%$ MBS. After injection the embryos were cultured in $4 \%$ ficoll, $1 \%$ MMR until stage $8 / 9$ and subsequently 
transferred to $1 \%$ MMR with or without ligands to culture the embryos until the appropriate stage.

\section{Lineage tracing}

Sulforhodamine dextran (MW 10,000) (S-359, Molecular Probes) was injected in all four macromeres of 8 cells stage embryos, $1 \mathrm{nl}$ of $5 \mathrm{ng} / \mathrm{nl}$ each injection, as described above. Embryos were cultured and allowed to develop until st. 40, when they were collected and fixed in MEMPFA, all as described above. They were stored in methanol at $-20^{\circ} \mathrm{C}$ until required. For histology sections, embryos were briefly transferred to $100 \%$ ethanol, subsequently cleared in Histo-Clear (National diagnostics) for about $25 \mathrm{~min}$ at room temperature, followed by graded immersion in paraffin at $60^{\circ} \mathrm{C}$ and incubation in $100 \%$ paraffin overnight at $60^{\circ} \mathrm{C}$. Next day samples were embedded and allowed to solidify at $4^{\circ} \mathrm{C}$ for approximately 1 hour. Prior to sectioning, they were placed outside the fridge to accommodate to room temperature. Histological sections were performed at $8 \mu \mathrm{m}$ of thickness, placed on slides pre-coated with BioBond according to the manufacturer (Electron Microscopy Sciences), on a drop of distilled water, then mildly heated on a heating plate until sections were nicely stretched; finally, they were placed at $37^{\circ} \mathrm{C}$ to dry completely. Sections were deparaffinised with Histo-Clear, gradually immersed into ethanol and subsequently hydrated, to be mounted in gelvatol containing DAPCO. Analysis and photography was performed by means of an AxioPlan 2 Imaging compound microscope and the corresponding software (Zeiss), provided with a TRITC band-pass filter.

\section{Immunofluorescence and confocal microscopy}

For immunostaining of the CNS, embryos were fixed overnight at $4^{\circ} \mathrm{C}$ in methanol. Pigmentation was bleached in $80 \%$ methanol, $6 \% \mathrm{H}_{2} \mathrm{O}_{2}, 15$ $\mathrm{mM} \mathrm{NaOH}$, for approximately 1 hour. After bleaching, the embryos were washed four times $15 \mathrm{~min}$ in PBS containing $0.2 \%$ Tween, and blocked for 30 min with PBT $(0.2 \%$ Tween, $3 \%$ bovine serum albumin in PBS). Incubation with the anti-neural antibodies 2G9 (Jones and Woodland, 1989) and Xen-1 (Ruiz I Altaba, 1992) at 1:1 2G9 and 1:5 Xen-1 in PBT was overnight at $4^{\circ} \mathrm{C}$. The embryos were washed four times $30 \mathrm{~min}$ at room temperature in PBT. Incubation with the secondary antibody conjugated to the Cy- 5 far-red fluorophore (Jackson Research Labs, Inc.) was overnight at $4^{\circ} \mathrm{C}$. After washing four times $30 \mathrm{~min}$ in PBS containing $0.2 \%$ Tween at room temperature, the embryos were fixed in methanol and cleared in 1:2 benzyl alcohol:benzyl benzoate. The Cy-5 signal was analysed with confocal laser scanning microscopy (CSLM). Approximately 25 optical sections were recorded for each embryo, and reconstructed into one image.

\section{Luciferase assay}

For measuring the luciferase activity 5-10 embryos were homogenised in 100:1 reporter lysis buffer (Promega) and mixed with 300:1 assay buffer (0.1 M potassium phosphate buffer pH 7.8 (KPi), 1 mM DTT, 3 mM ATP and $\left.15 \mathrm{mM} \mathrm{MgSO}_{4}\right)$. The luciferase reaction was started by addition of 100:1 0.1 M KPi, 1 mM DTT and $0.4 \mathrm{mM}$ luciferine. Light units were measured during 10 seconds in a luminometer (Biocounter, Lumac).

\section{In situ hybridisation}

Whole-mount in situ hybridisation (w-ISH) on Xenopus embryos was performed as previously described (Harland, 1991), except that probe concentration was reduced to $40 \mathrm{ng} / \mathrm{ml}$, hybridisation temperature raised to $65^{\circ} \mathrm{C}$ and antibody incubations done in $0.1 \mathrm{M}$ Maleic acid, $0.15 \mathrm{M} \mathrm{NaCl}$, $0.1 \%$ Tween-20, $1 \%$ blocking reagent (Roche), $\mathrm{pH} 7.5$ with anti-Digoxigenin-AP, Fab fragments (Roche). Analysis of the staining pattern was performed in PBS or 1:2 benzyl alcohol:benzyl benzoate to clear the embryos.

w-ISH on quail embryos was performed as previously described (Stern, 1998) for chick embryos.

\section{Templates for RNA synthesis}

Xenopus antisense DIG-labelled transcripts were prepared from the following templates: a 1312 bp Hoxa-1fragment (Hoxa- 1), a 666 bp Hoxb1 fragment (Hoxb-1), xHoxlab1 (Hoxd-1) (Sive and Cheng, 1991), EST: dac02e11 (Hoxd-3), a 708 bp fragment containing the complete Hoxb-4 ORF (Hoxb-4), EST: XL045g13 (Hoxa-5), a 998 bp Hoxc-6 fragment in pGEM1 containing a part of the homeodomain and extending into the 3 ' UTR (Hoxc-6), a 470 bp Hoxb-9fragment in pGEM3 (Hoxb-9), a 1400 bp Krox-20fragment (Krox-20) (Bradley et al., 1993), a 1500bp Engrailed-2 cDNA (En-2) (Hemmati-Brivanlou et al., 1991), the XIPOU 2ORF (XIpou 2) (Witta et al., 1995), the Xcad-3 ORF (Xcad-3) (Pownall et al., 1996), the xCRABP ORF (xCRABP) (Dekker et al., 1994) and a 220 bp OTX-2 fragment (XOTX-2) (Pannese et al., 1995).

Chick antisense DIG-labelled transcripts were used for w-ISH on quail embryos, prepared from the following templates: a $2 \mathrm{~Kb} H o x b 1 \mathrm{cDNA}$ and a Hoxb4 (Bel-Vialar et al., 2002).

\section{Acknowledgements}

We would like to thank Nobue Itasaki for kindly providing us with the chick Hoxb1 cDNA, as well as Robb Krumlauf for the chick Hoxb4. We are also grateful with Gerda Lamers for her technical assistance and advice on histological sections and microscopy. AJD and CS acknowledge financial support from the EU network of excellence LSHM-CT-2003504468: Cells into Organs.

MHZ was supported by NIH Grant 5R01 HL61982-03, the National Research Initiative USDA Grant 2005-35200-15257 and the Michigan Agricultural Experiment Station.

\section{References}

AGARWAL, C., CHANDRARATNA, R.A., JOHNSON, A.T., RORKE, E.A. and ECKERT, R.L. (1996). AGN193109 is a highly effective antagonist of retinoid action in human ectocervical epithelial cells. J.Biol.Chem. 271: 12209-12212.

AVANTAGgIATO, V., ACAMPORA, D., TUORTO, F. and SIMEONE, A. (1996). Retinoic acid induces stage-specific repatterning of the rostral central nervous system. Dev.Biol. 175: 347-357.

BEGEMANN, G., SCHILLING, T.F., RAUCH, G.J., GEISLER, R. and INGHAM, P.W. (2001). The zebrafish neckless mutation reveals a requirement for raldh2 in mesodermal signals that pattern the hindbrain. Development 128: 3081 3094.

BEL-VIALAR, S., ITASAKI, N. andKRUMLAUF, R. (2002). Initiating Hox gene expression: in the early chick neural tube differential sensitivity to FGF and RA signaling subdivides the HoxB genes in two distinct groups. Development 129: 5103-5115.

BERGGREN, K., MCCAFFERY, P., DRAGER, U. and FOREHAND C.J. (1999). Differential distribution of retinoic acid synthesis in the chicken embryo as determined by immunolocalisation of the retinoic acid synthetic enzyme RALDH2. Dev. Biol. 210: 288-304.

BLUMBERG, B., BOLADO, J.JR., MORENO, T.A., KINTNER, C., EVANS, R.M. and PAPALOPULU, N. (1997). An essential role for retinoid signaling in anteroposterior neural patterning. Development 124: 373-379.

BRADLEY, L.C., SNAPE, A., BHATT, S. and WILKINSON, D.G. (1993). The structure and expression of the Xenopus Krox-20 gene: conserved and divergent patterns of expression in rhombomeres and neural crest. Mech.Dev. 40: 73-84.

CARAPUCO, M., NOVOA, A., BOBOLA, N. and MALLO, M. (2005). Hox genes specify vertebral types in the presomitic mesoderm. Genes Dev. 19:2116-2121.

CHAMBON, P. (1996). A decade of molecular biology of retinoic acid receptors. FASEB J. 10: 940-954.

CHEN, Y., POLLET, N., NIEHRS, C. and PIELER, T. (2001). Increased XRALDH2 activity has a posteriorizing effect on the central nervous system of Xenopus embryos. Mech Dev. 101: 91-103.

CONLON, R.A. and ROSSANT, J. (1992). Exogenous retinoic acid rapidly induces 
anterior ectopic expression of murine Hox-2 genes in vivo. Development 116 : 357-368.

DEKKER, E.J., VAESSEN, M.J., VAN DEN BERG, C., TIMMERMANS, A., GODSAVE, S., HOLLING, T., NIEUWKOOP, P., GEURTS, V.K. and DURSTON, A. (1994). Overexpression of a cellular retinoic acid binding protein (xCRABP) causes anteroposterior defects in developing Xenopus embryos. Development 120: 973-985.

DERSCH, H. and ZILE, M.H. (1993). Induction of normal cardiovascular development in the vitamin A-deprived quail embryo by natural retinoids. Dev Bio/160: 424-433.

DESCHAMPS, J. and WIJGERDE, M. (1993). Two phases in the establishment of HOX expression domains. Dev Biol156: 473-480.

DONIACH, T. (1995). Basic FGF as an inducer of anteroposterior neural pattern. Cel/83: 1067-1070.

DUPE, V. and LUMSDEN, A. (2001). Hindbrain patterning involves graded responses to retinoic acid signalling. Development 128: 2199-2208.

DURSTON, A.J., TIMMERMANS, J.P., HAGE, W.J., HENDRIKS, H.F., DE VRIES, N.J., HEIDEVELD, M. and NIEUWKOOP, P.D. (1989). Retinoic acid causes an anteroposterior transformation in the developing central nervous system. $\mathrm{Na}$ ture 340: 140-146

DURSTON, A.J., VAN DER WEES, J., PIJNAPPEL, W.W. and GODSAVE, S.F. (1998). Retinoids and related signals in early development of the vertebrate central nervous system. Curr. Top.Dev.Biol. 40: 111-175.

GAUNT, S.J. and STRACHAN, L. (1996). Temporal colinearity in expression of anterior Hox genes in developing chick embryos. Dev Dyn. 207: 270-280.

GAVALAS, A. and KRUMLAUF, R. (2000). Retinoid signalling and hindbrain patterning. Curr.Opin.Genet.Dev. 10: 380-386.

GODSAVE, S.F. and DURSTON, A.J. (1997). Neural induction and patterning in embryos deficient in FGF signaling. Int.J.Dev.Biol. 41: 57-65.

GodsaVe, S.F., KOSTER, C.H., GETAHUN, A., MATHU, M., HOOIVELD, M., VAN DER WEES, J., HENDRIKS, J. and DURSTON, A.J. (1998). Graded retinoid responses in the developing hindbrain. Dev.Dyn. 213: 39-49.

GOULD, A., ITASAKI, N. and KRUMLAUF, R. (1998). Initiation of rhombomeric Hoxb4 expression requires induction by somites and a retinoid pathway. Neuron 21: 39-51.

GRANDEL, H., LUN, K., RAUCH, G.J., RHINN, M., PIOTROWSKI, T., HOUART, C., SORDINO, P., KUCHLER, A.M., SCHULTE-MERKER, S., GEISLER, R. et al. (2002). Retinoic acid signalling in the zebrafish embryo is necessary during pre-segmentation stages to pattern the anterior-posterior axis of the CNS and to induce a pectoral fin bud. Development 129: 2851-2865.

HARLAND, R.M. (1991). In situhybridization: an improved whole-mount method for Xenopus embryos. Methods. Cell.Biol. 36: 685-695.

HASELBECK, R.J., HOFFMANN, I. and DUESTER, G. (1999). Distinct functions for Aldh1 and Raldh2 in the control of ligand production for embryonic retinoid signaling pathways. Dev Genet. 25: 353-364.

HELMBACHER, F., PUJADES, C., DESMARQUET, C., FRAIN, M., RIJLI, F.M., CHAMBON, P. and CHARNAY, P. (1998). Hoxa1 and Krox-20 synergize to control the development of rhombomere 3. Development 125: 4739-4748.

HEMMATI-BRIVANLOU, A., DE LA TORRE, J., HOLT, C. and HARLAND, R.M. (1991). Cephalic expression and molecular characterization of Xenopus En-2. Development 111: 715-724.

HERNANDEZ, R.E., PUTZKE, A.P., MYERS, J.P., MARGARETHA, L. and MOENS, C.B. (2007). Cyp26 enzymes generate the retinoic acid response pattern necessary for hindbrain development. Development 134: 177-187.

HOLLEMANN, T., CHEN, Y., GRUNZ, H. and PIELER, T (1998). Regionalized metabolic activity establishes boundaries of retinoic acid signalling. EMBO.J. 17: 7361-7372

ITASAKI, N., SHARPE, J., MORRISON, A. and KRUMLAUF, R. (1996). Reprogramming Hox expression in the vertebrate hindbrain: influence of paraxial mesoderm and rhombomere transposition. Neuron 16: 487-500.

JONES, E.A., and WOODLAND, H.R. (1989). Spatial aspects of neural induction in Xenopus laevis. Development 107: 785-791.

KOLM, P.J., APEKIN, V. and SIVE, H. (1997). Xenopus hindbrain patterning requires retinoid signaling. Dev Bio/192: 1-16.

KUDOH, T., WILSON, S.W. and DAWID, I.B. (2002). Distinct roles for Fgf, Wnt and retinoic acid in posteriorizing the neural ectoderm. Development 129: 4335 4346.

LUMSDEN, A. and KRUMLAUF, R. (1996). Patterning the vertebrate neuraxis. Science 274: 1109-1115.

MADEN, M., GALE, E., KOSTETSKII, I. and ZILE, M. (1996). Vitamin A-deficient quail embryos have half a hindbrain and other neural defects. Curr.Biol. 6: 417426.

MARSHALL, H., MORRISON, A., STUDER, M., POPPERL, H. and KRUMLAUF, R. (1996). Retinoids and Hox genes. FASEB J10: 969-978.

MCGREW, L.L., HOPPLER, S. and MOON, R.T. (1997). Wnt and FGF pathways cooperatively pattern anteroposterior neural ectoderm in Xenopus. Mech.Dev. 69: 105-114.

NIEDERREITHER, K., SUBBARAYAN, V., DOLLE, P. and CHAMBON, P. (1999). Embryonic retinoic acid synthesis is essential for early mouse post-implantation development. Nat.Genet. 21: 444-448.

NIEDERREITHER, K., VERMOT, J., SCHUHBAUR, B., CHAMBON, P. and DOLLE, $P$. (2000). Retinoic acid synthesis and hindbrain patterning in the mouse embryo. Development 127: 75-85.

NIEUWKOOP, P.D. (1952). Activation and organisation of the central nervous system in amphibians. III. Synthesis of a new working hypothesis. J.Exp.Zool. 120: 83-108.

NIEUWKOOP, P.D. and FABER, J. (Eds.) (1956). Normal table of Xenopus laevis (Daudin). North-Holland Publishing Company, Amsterdam.

NORDSTRÖM, U., MAIER, E., JESSELL, T.M. and EDLUND, T. (2006). An Early Role for Wnt Signaling in Specifying Neural Patterns of $C d x$ and Hox Gene Expression and Motor Neuron Subtype Identity. In PLoS Bio/vol. 4(8): e252 (ed.

PANNESE, M., POLO, C., ANDREAZZOLI, M., VIGNALI, R., KABLAR, B., BARSACCHI, G. and BONCINELLI, E. (1995). The Xenopushomologue of Otx2 is a maternal homeobox gene that demarcates and specifies anterior body regions. Development 121: 707-720.

POWNALL, M.E., TUCKER, A.S., SLACK, J.M. and ISAACS, H.V. (1996). eFGF, $X$ cad3and Hox genes form a molecular pathway that establishes the anteroposterior axis in Xenopus. Development 122: 3881-3892.

RAMIREZ-SOLIS, R., ZHENG, H., WHITING, J., KRUMLAUF, R. and BRADLEY, A. (1993). Hoxb-4 (Hox-2.6) mutant mice show homeotic transformation of a cervical vertebra and defects in the closure of the sternal rudiments. Ce//73(2): 279-294.

RIJLI, F.M., MATYAS, R., PELLEGRINI, M., DIERICH, A., GRUSS, P., DOLLE, P. and CHAMBON, P. (1995). Cryptorchidism and homeotic transformations of spinal nerves and vertebrae in Hoxa-10 mutant mice. Proc Nat/ Acad SciUSA. 92(18): 8185-8189.

RUIZ I ALTABA, A. (1992). Planar and vertical signals in the induction and patterning of the Xenopus nervous system. Development 116: 67-80.

SIVE, H., GRAINGER, R.M. and HARLAND, R. (Eds.) (1998). Early Development of Xenopus laevis - A Laboratory Manual. Cold Spring Harbor Laboratory Press, New York.

SIVE, H.L., and CHENG, P.F. (1991). Retinoic acid perturbs the expression of Xhox.labgenes and alters mesodermal determination in Xenopus laevis. Genes Dev. 5: 1321-1332.

SIVE, H.L., DRAPER, B.W., HARLAND, R.M. and WEINTRAUB, H. (1990). Identification of a retinoic acid-sensitive period during primary axis formation in Xenopus laevis. Genes.Dev. 4: 932-942.

STERN, C.D. (1998). Detection of multiple gene products simultaneously by in situ hybridization and immunohistochemistry in whole mounts of avian embryos. Curr Top Dev Biol. 36: 223-243.

SUBRAMANIAN V., MEYER, B.I. and GRUSS, P. (1995). Disruption of the murine homeobox gene $\mathrm{Cdx} 1$ affects axial skeletal identities by altering the mesodermal expression domains of Hox genes. Cel/83(4): 641-653.

SWINDELL E.C., THALLER, C., SOCKANATHAN, S., PETKOVITCH, M., JESSEL, T.M. and EICHELE G. (1999). Complementary domains of retinoic acid production and degradation in the early chick embryo. Dev. Biol. 216: 282-296.

THEIL, T., FRAIN, M., GILARDI-HEBENSTREIT, P., FLENNIKEN, A., CHARNAY, P. and WILKINSON, D.G. (1998). Segmental expression of the EphA4 (Sek-1) receptor tyrosine kinase in the hindbrain is under direct transcriptional control of Krox-20. Development 125: 443-452. 
VAN DER WEES, J., SCHILTHUIS, J.G., KOSTER, C.H., DIESVELD-SCHIPPER, H., FOLKERS, G.E., VAN DER SAAG, P.T., DAWSON, M.I., SHUDO, K., VAN DER, B.B. and DURSTON, A.J. (1998). Inhibition of retinoic acid receptormediated signalling alters positional identity in the developing hindbrain. Deve/opment 125: 545-556.

VESQUE, C., MACONOCHIE, M., NONCHEV, S., ARIZA-MCNAUGHTON, L., KUROIWA, A., CHARNAY, P. and KRUMLAUF, R. (1996). Hoxb-2 transcriptional activation in rhombomeres 3 and 5 requires an evolutionarily conserved cis-acting element in addition to the Krox-20 binding site. EMBO J15: 53835396.
WACKER, S.A., JANSEN, H.J., MCNULTY, C.L., HOUTZAGER, E. and DURSTON, A.J. (2004). Timed interactions between the Hox expressing non-organiser mesoderm and the Spemann organiser generate positional information during vertebrate gastrulation. Dev Biol. 268: 207-219.

WITTA, S.E., AGARWAL, V.R. and SATO, S.M. (1995). XIPOU 2, a noggininducible gene, has direct neuralizing activity. Development 121: 721-730.

ZILE, M.H., KOSTETSKII, I., YUAN, S., KOSTETSKAIA, E., ST. AMAND, T.R., CHEN, Y. and JIANG, W. (2000). Retinoid signaling is required to complete the vertebrate cardiac left/right asymmetry pathway. Dev Bio/223: 323-338.
Further Related Reading, published previously in the Int. J. Dev. Biol.

See Special Issue Pattern Formation edited by Michael K. Richardson and ChengMing Chuong at:

http://www.ijdb.ehu.es/web/contents.php?vol=53\&issue=5-6

The road to the vertebral formula

Moisés Mallo, Tânia Vinagre and Marta Carapuço

Int. J. Dev. Biol. (2009) 53: 1469-1481

Retinoic acid metabolizing factor xCyp26c is specifically expressed in neuroectoderm and regulates anterior neural patterning in Xenopus laevis Misaki Tanibe, Tatsuo Michiue, Akira Yukita, Hiroki Danno, Masayuki Ikuzawa, Shoichi Ishiura and Makoto Asashima

Int. J. Dev. Biol. (2008) 52: 893-901

The retinoic acid metabolising gene, CYP26B1, patterns the cartilaginous cranial neural crest in zebrafish

Susan Reijntjes, Adam Rodaway and Malcolm Maden

Int. J. Dev. Biol. (2007) 51: 351-360

Head-tail patterning of the vertebrate embryo: one, two or many unresolved problems?

Claudio D. Stern, Jeroen Charité, Jacqueline Deschamps, Denis Duboule, Anthony J. Durston, Marie Kmita, Jean-François Nicolas, Isabel Palmeirim, Jim C. Smith and Lewis Wolpert

Int. J. Dev. Biol. (2006) 50: 3-15

Retinoid signalling acts during the gastrula stages to promote primary neurogenesis.

C Sharpe and K Goldstone

Int. J. Dev. Biol. (2000) 44: 463-470

Evolutionary shifts of vertebrate structures and Hox expression up and down the axial series of segments: a consideration of possible mechanisms.

S J Gaunt

Int. J. Dev. Biol. (2000) 44: 109-117

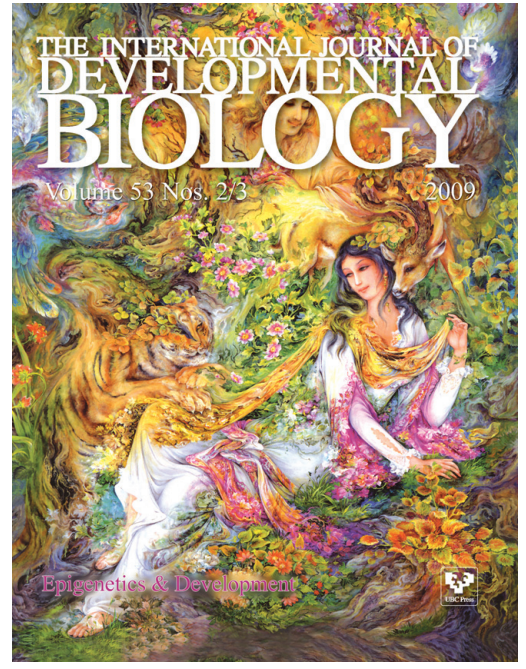

5 yr ISI Impact Factor $(2008)=3.271$

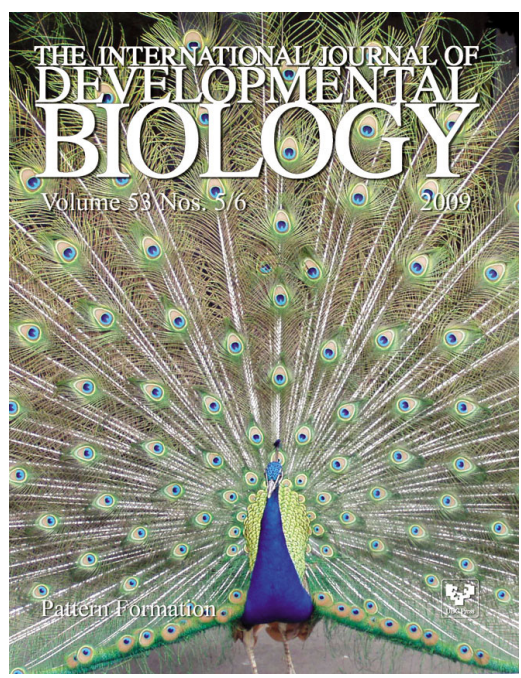

